\title{
Lung mast cells in plexogenic pulmonary arteriopathy
}

D Heath, M Yacoub

\begin{abstract}
The numbers of mast cells $/ \mathrm{mm}^{2}$ of lung parenchyma were counted in four controls, 15 cases of primary plexogenic pulmonary arteriopathy (PPA), and 17 cases in which the arteriopathy was secondary to congenital heart disease, to determine if increased numbers occur in PPA and with what stage of disease they might be associated. Considerable accumulations of lung mast cells may occur in this disease, but these are not closely related to any particular histological stage in the development of the arteriopathy.

It is postulated that while mast cells could conceivably exert a vasodilatory effect on constricted small pulmonary arteries, it seems more likely that they are part of the parenchymal changes that commonly develop in this disease.
\end{abstract}

Much has been written on the pathology of plexogenic pulmonary arteriopathy (PPA), but until recently this has been restricted almost entirely to a consideration of the histopathology or ultrastructure of the pulmonary blood vessels. In fact, a wide range of histological changes develops in the lung substance in this disease including alveolar macrophages and siderophages, cholesterol granulomas, lymphoid tissue and periarterial lymphocytes. ${ }^{1}$ Other parenchymal lesions found include haemorrhages, prominence of granular pneumonocytes, early pulmonary fibrosis, dystrophic calcification, metaplastic bone formation and the appearance of cells resembling meningocytes around pulmonary venules. ${ }^{1}$ Increased numbers of pulmonary endocrine cells containing gastrin-releasing peptide and calcitonin appear in the bronchiolar epithelium and alveolar walls and are related to the stage reached in the development of plexogenic pulmonary arteriopathy. ${ }^{2}$ These neuroendocrine cells are most numerous and prominent when the plexiform lesions are large and cellular, and in the pre-plexiform stage when muscle cells are migrating from the media into the intima.

Mast cells characteristically accumulate in the lung parenchyma in conditions of pulmonary arterial with capillary hypertension such as is found in mitral stenosis ${ }^{3}$ and following the administration of pyrrolizidine alkaloids." A similar accumulation also occurs in animals subjected to hypoxia in experimental conditions in the laboratory ${ }^{5}$ or on exposure to the hypobaric hypoxia of natural high altitude. ${ }^{6}$

\section{Methods}

Thirty six cases were studied. Four (cases 1-4) in the age range 21-29 years were controls, three of whom had died in road accidents. Seventeen (cases 5-21), in the age range 6-39 years, were patients with PPA secondary to various forms of congenital cardiac septal defect (table 1). The remaining 15 (cases 2236 ), in the age range 4-46 years, were patients with primary plexogenic pulmonary arteriopathy (table). Cases of the arteriopathy which may, rarely, be associated with cirrhosis of the liver or portal vein thrombosis were not available for study.

The lungs became available at combined heart and lung transplantation. In each case a slice of lung fixed in $10 \%$ formalin was received in the laboratory. Under ideal conditions, such as might be obtained in animal experiments, the lungs would have been distended with fixative until the pleural surfaces were smooth, to allow accurate determination of the absolute numbers of mast cells present. The fixative of choice would have been methanol because human mast cell granules are slightly soluble in aqueous solutions of formaldehyde. To take the opportunity of studying this unusual pulmonary tissue at surgery, however, it was necessary to accept less than ideal conditions of distension and fixation. As all the specimens were processed in the same way it was thought that the results of quantitation were valid for purposes of comparison, although the absolute numbers might be marginally smaller than if fixed in methanol. Three blocks of the slice of lung from each patient were used for this study.

Paraffin wax sections of $5 \mu \mathrm{m}$ in thickness were stained with a solution of $2 \%$ toluidine blue in $5 \%$ aluminium sulphate which is a highly specific stain for the detection of sulphated mucopolysaccharides in tissue sections. ${ }^{7}$ Using this technique, mast cell granules stain deeply metachromatically, producing a magenta red colour in contrast to a pale blue background, a striking tinctorial contrast, which facilitates their recognition and counting. The staining of the mast cells was strongly positive and their granules were sharply defined so that in practical terms the fixation in formalin seemed to have presented no problem.

It has been suggested that the staining of mast cells in heterogeneous mast cell subpopulations may differ after formalin fixation. Thus Wingren and Enerbäck showed that in rats the mucosal mast cells of the gastrointestinal tract constitute a separate cell line. ${ }^{8}$ After fixation in formalin, unlike typical connective 
Age, sex, cause of death or diagnosis, numbers of mast cells/mm ${ }^{2}$ of lung and state of plexiform lesions

\begin{tabular}{|c|c|c|c|c|c|}
\hline Case No & Age & Sex & Cause of death, or diagnosis & Mast cells/mm $\mathbf{m}^{2}$ & State of plexiform lesions \\
\hline \multicolumn{6}{|c|}{ Control subjects } \\
\hline 1 & 21 & $\mathbf{M}$ & Road accident & 3.8 & Nil \\
\hline 2 & 23 & $\mathrm{M}$ & Road accident & 8.8 & Nil \\
\hline 3 & 24 & $\mathrm{M}$ & Road accident & 0.6 & Nil \\
\hline 4 & 29 & $\mathrm{~F}$ & Friedreich's ataxia & 8.8 & Nil \\
\hline \multicolumn{6}{|c|}{ Secondary plexogenic pulmonary arteriopathy } \\
\hline 5 & 6 & $\mathbf{F}$ & Aortopulmonary window & $102 \cdot 5$ & C \\
\hline 6 & 11 & $\mathbf{F}$ & Double inlet ventricle & $17 \cdot 2$ & $\mathbf{s}$ \\
\hline 7 & 12 & $\mathbf{F}$ & Single ventricle & 47.0 & C \\
\hline 8 & 13 & $\mathbf{F}$ & Double inlet ventricle & 113.8 & C \\
\hline 9 & 15 & $\mathbf{F}$ & Transposition and ventricular septal defect & $94 \cdot 1$ & $\mathrm{C}$ \\
\hline 10 & 15 & $M$ & Double inlet ventricle & 106.7 & $\mathbf{P}$ \\
\hline 11 & 19 & $\mathbf{F}$ & Waterston shunt & $45 \cdot 6$ & $\mathbf{s}$ \\
\hline 12 & 21 & $\mathbf{F}$ & Ventricular septal defect & 73.9 & C \\
\hline 13 & 23 & $\mathbf{F}$ & Ventricular septal defect (repaired) & 81.5 & $\mathbf{S}$ \\
\hline 14 & 23 & $\mathbf{F}$ & Transposition & 68.0 & C \\
\hline 15 & 24 & $\mathbf{F}$ & Patent ductus arteriosus & $5 \cdot 9$ & C \\
\hline 16 & 24 & $\mathbf{M}$ & Transposition and ventricular septal defect & $6 \cdot 3$ & G \\
\hline 17 & 26 & $\mathbf{F}$ & Patent ductus arteriosus & 47.9 & $\mathbf{M}$ \\
\hline 18 & 26 & $\mathrm{~F}$ & Atrio-ventricular canal & $15 \cdot 1$ & $\mathbf{M}$ \\
\hline 19 & 33 & $\mathrm{~F}$ & Ventricular septal defect & 21.8 & S \\
\hline 20 & 39 & $\mathbf{F}$ & Atrio-ventricular canal defect & $25 \cdot 6$ & $\mathbf{s}$ \\
\hline 21 & 39 & $\mathbf{F}$ & Ventricular septal defect & $1 \cdot 1$ & $\mathbf{M}$ \\
\hline \multicolumn{6}{|c|}{ Primary plexogenic pulmonary arteriopathy } \\
\hline 22 & 4 & $\mathrm{~F}$ & & $58 \cdot 2$ & $P$ \\
\hline 23 & 6 & $\mathbf{F}$ & & 73.9 & C \\
\hline 24 & 12 & $\mathbf{M}$ & & 48.7 & C \\
\hline 25 & 16 & $\mathbf{F}$ & & $27 \cdot 3$ & C \\
\hline 26 & 17 & $\mathbf{F}$ & & $75 \cdot 6$ & C \\
\hline $\begin{array}{l}27 \\
28\end{array}$ & 18 & $\mathbf{F}$ & & $50 \cdot 4$ & C \\
\hline $\begin{array}{l}28 \\
29\end{array}$ & $\begin{array}{l}19 \\
22\end{array}$ & $\mathbf{F}$ & Primary PPA & $\begin{array}{l}93.1 \\
81.1\end{array}$ & $\begin{array}{l}\text { C } \\
\text { P }\end{array}$ \\
\hline $\begin{array}{l}29 \\
30\end{array}$ & 23 & $\mathbf{M}$ & & $27 \cdot 3$ & C \\
\hline 31 & 29 & $\mathbf{M}$ & & $22 \cdot 3$ & C \\
\hline 32 & 30 & $\mathbf{M}$ & & 113.8 & $\mathbf{S}$ \\
\hline 33 & 32 & $\mathbf{F}$ & & 65.5 & $\mathbf{P}$ \\
\hline 34 & 36 & $F$ & & 8.4 & $\mathbf{S}$ \\
\hline $\begin{array}{l}35 \\
36\end{array}$ & $\begin{array}{l}38 \\
46\end{array}$ & $\stackrel{\mathbf{M}}{\mathbf{F}}$ & & $\begin{array}{l}40.3 \\
73.5\end{array}$ & $\stackrel{\mathbf{S}}{\mathbf{C}}$ \\
\hline
\end{tabular}

Code: $\mathrm{C}=$ cellular plexiform lesions; $\mathrm{S}=$ small and sparse plexiform lesions; $\mathrm{P}=$ preplexiform lesions; $\mathrm{M}=$ mature plexiform lesions.

tissue mast cells, they require prolonged staining with toluidine blue for up to a week to become apparent. Such a problem is unlikely to have vitiated the results of the present investigation because so far as the authors are aware there have been no reports to suggest that different mast cell subpopulations are associated with human pulmonary vascular disease. Certainly in other human organs, such as the uterus, the heterogeneity of histological properties of mast cells is more likely to reflect their functional state than a subpopulation. ${ }^{9}$

The sections of lungs were systematically scanned and mast cell counts made using an eyepiece graticule that had been calibrated with a stage micrometer. The squared graticule, itself subdivided into 100 small squares, was used on 20 areas of lung so that the mast cell content of 2000 small squares was counted in each case (fig 1). As a consequence the density of mast cells $/ \mathrm{mm}^{2}$ of the histological sections of lung was calculated. The area of one of the squares was $2.37 \times 10^{-3} / \mathrm{mm}^{2}$ so that the total area of lung studied in each case was $4.74 / \mathrm{mm}^{2}$.

In each case the stage of PPA reached was recorded. The term "plexogenic" implies that the disease has the potential for forming plexiform lesions but that they need not be present for the diagnosis to be made. In the preplexiform stage there was migration of vascular smooth muscle cells into the intima where they had undergone transformation into myofibroblasts which occluded small pulmonary arterial vessels. Cellular plexiform lesions were characterised by patchy fibrinoid necrosis in the parent pulmonary arteries and a proliferation of cells in dilated arterial branches around vessels of capillary diameter arranged in a plexiform pattern. The cells comprised myofibroblasts and primitive cells with a cytoplasm rich in filaments. Mature plexiform lesions showed wide vascular channels with thicker septa composed of fibrous and elastic tissue so that they bore a histological resemblance to recanalised thrombus. Finally, in some of the cases the plexiform lesions were small and sparse (table). We have already discussed the histological features of these different stages of PPA. ${ }^{1}$ It was possible to

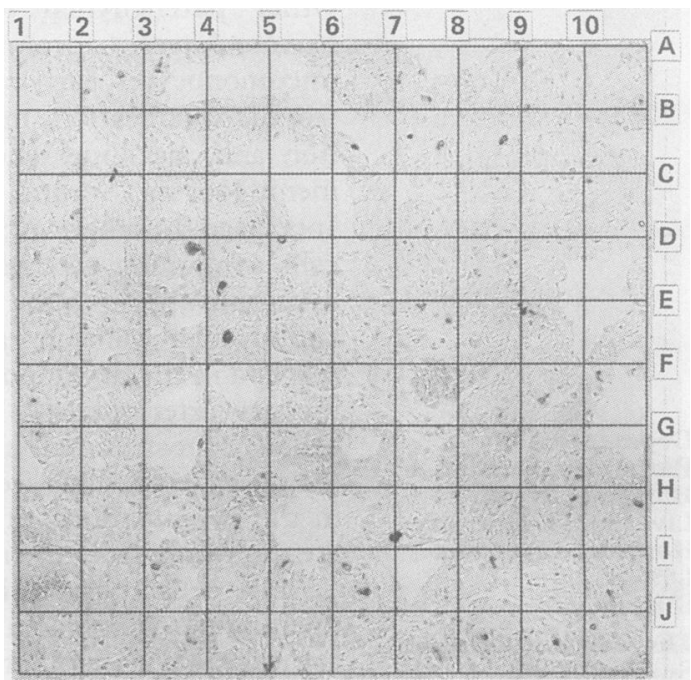

Figure 1 Method used to count mast cells. The cells are very clearly shown by staining with toluidine blue and aluminium sulphate. The numbers present were counted in 100 small squares previously calibrated by a stage micrometer. The graticule was used to study 20 randomly selected areas of lung parenchyma (toluidine bluealuminium sulphate). 
Figure 2 Case 32: male, aged 30 years, with primary pulmonary hypertension. Mast cells are scattered in the lung parenchyma (toluidine blue-aluminium sulphate). Scale line $=33 \mu \mathrm{m}$.

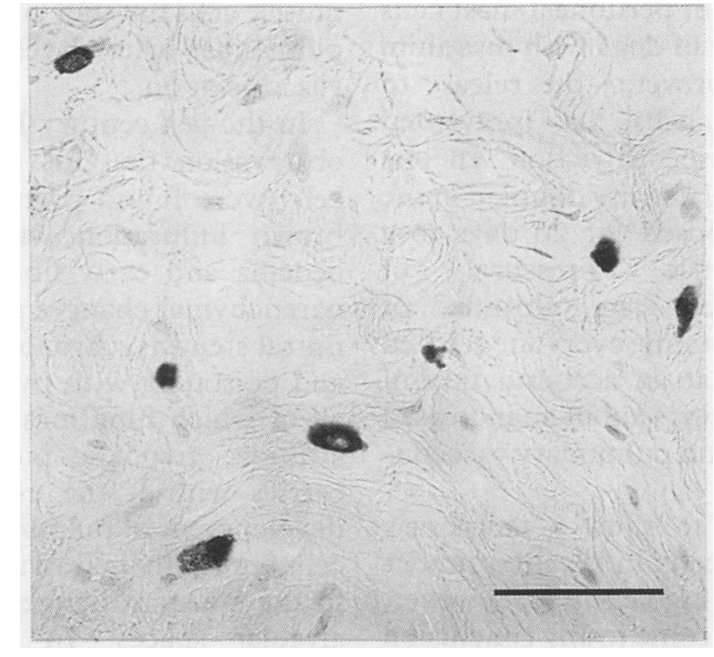

relate the number of mast cells $/ \mathrm{mm}^{2}$ in the lung to the stage of PPA reached in each of the 32 cases.

\section{Results}

QUALITATIVE

In the control cases scanty mast cells were found scattered diffusely or in small focal collections within the perivascular and subpleural connective tissues of the lung. In the cases of PPA mast cells were also found in these sites but in greater profusion (fig 2). They also commonly extended into the secondary connective tissue septa of the lung and in the walls of bronchioles. Most importantly, however, they were found extensively throughout the lung parenchyma. Even here, however, they were more numerous in the adventitia of small pulmonary blood vessels.

\section{QUANTITATIVE}

The numbers of mast cells $/ \mathrm{mm}^{2}$ of lung parenchyma are shown in the table. Considerable numbers of mast cells were found in both primary PPA and in the form secondary to congenital heart disease. In the primary form the numbers ranged widely from 8.4-113.8/ $\mathrm{mm}^{2}$ with a mean value of $57 \cdot 3 / \mathrm{mm}^{2}$ (SD 29.0). In the secondary form there was also a wide range from $1 \cdot 1-113 \cdot 8 / \mathrm{mm}^{2}$ with a mean value of $51.4 / \mathrm{mm}^{2}$ (SD $38 \cdot 6$ ). For eight cases with sparse numbers of plexiform lesions the range was $8 \cdot 4-113 \cdot 8 / \mathrm{mm}^{2}$ and the mean $44 \cdot 3 / \mathrm{mm}^{2}$. In 17 cases with cellular plexiform lesions the range was $5.9-113.8 \mathrm{~mm}^{2}$ and the mean was $59.0 / \mathrm{mm}^{2}$ (SD 33.1). In three cases with mature plexiform lesions the range was $1 \cdot 1$ $47 \cdot 9 / \mathrm{mm}^{2}$ with a mean of $21 \cdot 4 / \mathrm{mm}^{2}$. In four cases in the preplexiform stage of the arteriopathy the range was $58 \cdot 2-106.7 / \mathrm{mm}^{2}$ with a mean of $77 \cdot 9 / \mathrm{mm}^{2}$.

\section{Discussion}

At the end of the last century Ehrlich and Westphal made the original observations that mast cells abound in the "brown induration" of the lung, according to Riley. ${ }^{10}$ In a previous investigation we confirmed these classic observations by quantitative studies which showed that the number of mast cells rose from a range of $1 \cdot 5-7 \cdot 7 / \mathrm{mm}^{2}$ (mean $3 \cdot 7$ ) in 12 control subjects without cardiopulmonary disease to a range of $18.1-99.0 / \mathrm{mm}^{2}$ (mean 41.9 ) in 11 subjects with chronic rheumatic valve disease, two with chronic left ventricular failure, and one with chronic pulmonary oedema and haemorrhage associated with a ventricular septal defect. ${ }^{3}$ In these cases of mitral valve disease and left ventricular failure there was combined pulmonary arterial and venous hypertension with increased pressure in the pulmonary capillaries and the parenchymal changes characteristically associated with pulmonary venous hypertension. ${ }^{11}$

Similarly, mast cell accumulation is found in the lungs of rats with pulmonary arterial and capillary hypertension induced by feeding them on Crotalaria spectabilis seeds which contain the pyrrolizidine alkaloid, monocrotaline, which after metabolism in the liver induces vasoconstriction. ${ }^{12}$ Subsequently we were able to show that, when rats are fed on these seeds, they all develop right ventricular hypertrophy, but only a proportion of them show an accumulation of mast cells in the lung. ${ }^{4}$ This suggested to us that the increased numbers of mast cells represent a reaction to the proliferative lesions which develop in the lungs of rats secondary to the terminal onset of congestive cardiac failure with pulmonary capillary hypertension. We found the mean mast cell count in 22 control animals to be $3 / \mathrm{mm}^{2}$; the mean count in 21 test rats was $78 / \mathrm{mm}^{2}$. The intimal fibromuscular pads, which are a normal feature of the pulmonary veins of the rat, are thickened in animals which have died of congestive heart failure after ingesting Crotalaria spectabilis seeds. Contraction of this muscle in the pulmonary veins might impede blood flow and result in the development initially of pulmonary venous and capillary hypertension with exudative lesions in the lung parenchyma and the accumulation of mast cells.

Subsequently, it has been shown that mast cells in the lung are not confined to the development of pulmonary arterial hypertension when this is associated with capillary hypertension and brown induration alone. It is now well established that mast cells are in some way related to the development of muscle in the peripheral portion of the pulmonary arterial tree which occurs in the presence of sustained alveolar hypoxia. It is not certain, however, whether the mast cells act as agents in initiating constriction of the small pulmonary arterial vessels or in relaxing them. Mast cells contain several vasoactive substances, including 5hydroxytryptamine and histamine. ${ }^{13}$ From the outset the evidence suggested that the former is not involved in the hypoxic response. ${ }^{1415}$ Gradually the concept developed that alveolar hypoxia causes mast cells to liberate the histamine that induced pulmonary vasoconstriction. Some authors found that histamine was released from animals' lungs during hypoxia, ${ }^{16}$ but no direct transmission of vasoconstriction was shown when the effluent of a hypoxic lung was passed through a second lung. Hypoxia has been shown to cause in vitro 
release of histamine from peritoneal mast cells in rats. ${ }^{16}$ The treatment of dogs with disodium cromoglycate, which prevents the release of histamine from mast cells, has prevented hypoxic pulmonary vasoconstriction. In one experiment the mast cell density doubled in the lungs of eight rats exposed for 20 days to a diminished barometric pressure of $380 \mathrm{~mm} \mathrm{Hg}$, simulating an altitude of 5500 metres. ${ }^{5} \mathrm{Up}$ to that time everyone seemed to support the idea that an accumulation of mast cells in the lung brings about an increased secretion of histamine and pulmonary vasoconstriction.

Although it is easy to show a temporary accumulation of mast cells in the lung under conditions of simulated high altitude, however, it is far more difficult to come to any conclusion as to what function they are fulfilling. The studies of Mungall showed that when rats were exposed to hypoxia, mast cells did not accumulate until after 21 days of exposure, but right ventricular hypertrophy was apparent after only 14 days, a rather unlikely event if the mast cells were instrumental in raising pulmonary vascular resistance leading to right ventricular hypertrophy. ${ }^{18} \mathrm{~A}$ major difficulty in accepting histamine from mast cells as the mediator of hypoxic pulmonary vasoconstriction is that its effect on the pulmonary circulation has not universally been shown to be constrictor. ${ }^{19}$ Indeed, the pharmacological evidence for active dilation of human pulmonary arteries is strong. ${ }^{20} \mathrm{It}$ would seem that $\mathrm{H} 2$ dilator receptors dominate in man as opposed to $\mathrm{H} 1$ constrictors.

On a more exotic note we found large numbers of periarteriolar and perivenular mast cells in a llama from Cerro de Pasco (4330 metres) in the high Andes of Peru. ${ }^{6}$ This species does not develop pulmonary hypertension in the hypobaric hypoxia of high altitude, and the perivascular accumulations of mast cells are consistent with their exerting a dilatory effect on the pulmonary arterial tree.

This study shows that mast cells appear in the lung in a third variety of pulmonary vascular disease-namely, PPA, occurring in equal numbers irrespective of whether this is primary or secondary to a congenital cardiac septal defect. They would probably also be found in the rare cases of the arteriopathy associated with cirrhosis of the liver or portal vein thrombosis. Mast cells are plentiful when the plexiform lesions are cellular but decline in number when these lesions mature. They are most numerous in the pre-plexiform stage of arteriopathy. The range in numbers of mast cells in the different stages of PPA, however, is wide so that a close relation cannot be established between the two.

We have recently pointed out that the basis for the increased pulmonary vascular resistance in PPA is twofold-namely, constriction of small pulmonary arteries, and occlusion of these vessels and of pulmonary arterioles by myofibroblasts in the lumen resulting from migration of smooth muscle cells from the media into the intima. ${ }^{1}$ Mast cells are most unlikely to be involved in this migration of muscle cells but they could affect the tone of the pulmonary arterial vessels in the direction of vasodilatation.

In the last century Ehrlich made his classic observation that his newly discovered mast cells were found prominently in the lung in brown induration with chronic pulmonary oedema and early fibrosis. Such widespread parenchymal changes are found in the lung in mitral stenosis, chronic left ventricular failure, and poisoning with pyrrolizidine alkoloids, in all of which lung mast cells abound. At high altitude, hypoxic pulmonary hypertension carries with it the ever-present risk of the development of pulmonary oedema ${ }^{21}$ and mast cells appear in this environment of a lung prone to the constant danger of exudation into the alveolar spaces. In plexogenic pulmonary arteriopathy a wide variety of parenchymal changes are also found, including alveolar macrophages and siderophages, haemorrhages, prominence of granular pneumonocytes, fibrosis of alveolar walls, dystrophic calcification and osseous nodules. It may well be that the accumulations of mast cells in the lung in PPA are thus but part of these parenchymal changes, just as Ehrlich found them to be so with the brown induration of mitral stenosis.

1 Caslin AW, Heath D, Madden B, Yacoub M, Gosney JR, Smith P. The histopathology of 36 cases of plexogenic pulmonary arteriopathy. Histopathology 1990;16:9-19.

2 Heath D, Yacoub M, Gosney JR, Madden B, Caslin AW, Smith P. Pulmonary endocrine cells in hypertensive Smith P. Pulmonary endocrine cells in hypertensive
pulmonary vascular disease. Histopathology 1990;16:21-8. pulmonary vascular disease. Histopathology 1990;16:21-8.
Heath D, Trueman T, Sukonthamarn P. Pulmonary mast cells in mitral stenosis. Cardiovasc Res 1969;3:467-71.
ceath D, Trueman T, Sukonthamarn P. Pulmonary mast

4 Kay JM, Gillund TD, Heath D. Mast cells in the lungs of rats fed on Crotalaria spectabilis seeds. Am J Pathol 1967;51:1031-44.

5 Kay JM, Waymire JC, Grover RF. Lung mast cell hyperplasia and pulmonary histamine-forming capacity in hypoxic rats. Am J Physiol 1974;226:178-84.

6 Williams A, Heath D, Harris P, Williams D, Smith P. Pulmonary mast cells in cattle and llamas at high altitude. J Pathol 1981;134:1-6.

7 Heath ID. Staining of sulphated mucopolysaccharides. Nature 1961;9:1370-1.

8 Wingren U, Enerbäck L. Mucosal mast cells of the rat intestine: a re-evaluation of fixation and staining properties, with special reference to protein blocking and solubility of the granular glycosaminoglycan. Histochem $J$ 1983;15:571-82.

9 Crow J, More L, Howe S. The mast cells of the human uterus. APMIS 1988;96:921-6.

10 Riley JF. The mast cells. Edinburgh: Churchill Livingstone, 1959:21-2,140-3

11 Heath D, Edwards JE. Histological changes in the lung in diseases associated with pulmonary venous hypertension. Br J Dis Chest 1959;53:8-18.

12 Takeoka O, Angevine DM, Lalich JJ. Stimulation of mast cells in rats fed various chemicals. Am J Pathol cells in rats $1962 ; 40: 545-54$.

13 Selye H. The mast cells. London: Butterworths, 1965.

14 Hauge A. Role of histamine in hypoxic pulmonary hypertension in the rat. I Blockade or potentiation of endogenous amines, kinins, and ATP. Circ Res 1968;22:371-83.

15 Bergofsky EH. Mechanisms underlying vasomotor regulation of regional pulmonary blood flow in normal and disease states. Am J Med 1974;57:378-94.

16 Haas F, Bergofsky EH. Role of the mast cell in the pulmonary pressor response to hypoxia. J Clin Invest 1972;51:3154-62.

17 Aviado DM, Samanek M, Folle LE. Cardiopulmonary effects of tobacco and related substances. I. The release of histamine during inhalation of cigarette smoke and anoxemia in the heart-lung and intact dog preparation. Arch Environ Health 1966;12:705-11.

18 Mungall IPF. Hypoxia and lung mast cells: influence of disodium cromoglycate. Thorax 1976;31:94-100.

19 Aviado DM. The lung circulation. vol.1 New York: Pergamon, 1965 .

20 Harris $P, H e a t h D$. The human pulmonary circulation. 3rd ed. Edinburgh: Churchill Livingstone, 1986:196-7.

21 Heath D, Williams DR. High altitude medicine and pathology. London: Butterworths, 1989. 